Leedy, M.G., \& Wilson, M.S. (1985). Testosterone and cortisol levels in crewmen of U.S. Air Force fighter and cargo planes. Psychosomatic Medicine, 47(4): 333-338. (July/August 1985). Published by Lippincott, Williams \& Wilkins (ISSN: 1534-7796).

\title{
Testosterone and Cortisol Levels in Crewmen of U.S. Air Force Fighter and Cargo Planes
}

Mitzi G. Leedy and Morgan S. Wilson

\begin{abstract}
Serum levels of cortisol and testosterone were measured in 39 United States Air Force personnel on active duty flying status. The subjects selected belonged to one of the following categories: pilot of a fighter-type aircraft, nonpilot on a fighter plane, pilot of a cargo-type aircraft, or nonpilot on a cargo plane. Blood samples were taken prior to and after a routine flying mission. Cortisol levels prior to the flight did not differ across groups. However, postflight samples of cortisol were elevated in the nonpitots, in comparison to the pilots, regardless of aircraft type. Conversely, while testosterone levels were unaffected by crew position, the men flying on fighter-type planes had lower serum levels than did those on cargo planes. These results suggest that hormone levels may be differentially affected by the stressors of routine military flight.
\end{abstract}


It is well known that environmental variables can influence hormone levels in animals, including man. In this regard there have been many attempts to elucidate the endocrine response of humans to psychologically stressful environments and to establish a physiologic correlate to psychogenie stress. Much of this research has been concerned with delineating the pituitaryadrenal response as measured by $17-$ OHCS secretion or serum cortisol, whereas more recent studies have also examined other hormonal systems, including androgens.

Many types of stressors have been shown to result in increased levels of cortisol or 17-OHCS. These can be acute, such as those experienced by naval aviators making their first carrier landings (1), army personnel making their first parachute jump (2), runners following a marathon (3), and underwater demolition teams during training with new equipment (4). Chronic stress can also result in increased levels of cortisol. Army personnel in Officer Candidate School had high levels of 17-OHCS during the stressful weeks of training (5). Also, air traffic controllers had high serum cortisol levels while at work (6).

Likewise, androgen levels can be affected by some of these same factors. Decreased levels of testosterone were found following endurance runs $(3,7)$, after surgery under general anesthesia (8), during training in Officer Candidate School (5), and before and after a first parachute jump (9).

The following report examines serum testosterone and cortisol levels in men who fly in a variety of United States Air Force aircraft. Two variables of particular interest are the type of aircraft used and whether or not the subject pilots the airplane. It seems logical that flying in a fighter-type aircraft would be more stressful than flying in a cargo-type plane. The effect of crew position on flight-induced endocrine response, however, is intuitively difficult to predict. It may be expected that pilots would experience elevated anxiety levels 
due to the increased level of responsibility that comes with commanding the aircraft, as suggested by previous studies $(1,6,10)$.

Conversely, Gal and Lazarus (11) have hypothesized

that the availability of a threatrelated

activity can reduce psychogenic

stress. Such an activity would primarily

be available only to the pilots. In order to

determine the role of these two factors-

activity and responsibility level—the present

study compared the endocrine response

to flight of pilots and nonpilots. By

controlling both crew position and aircraft

type, we hoped to further elucidate the

endocrine response to a mild psychogenic

stressor.

\section{METHODS}

\section{Subjects}

All subjects were males on active duty flying status, stationed at McClellan Air Force Base, USA, and were between the ages of 20 and 45 years. All had passed extensive physical examinations within the past 12 months, and all conformed to the height and weight standards set by the USAF for flying personnel. The 39 men, selected on a volunteer basis, consisted of 10 pilots and 7 nonpilots of fighter-type aircraft, and 11 pilots and 11 nonpilots of cargo-type aircraft. All pilots had completed their basic training prior to participation in this study.

The fighter-type planes included the F-III (dual seat fighter-bomber), the T-38A (dual seat fightertrainer), and the A-10 (single seat attack plane). Nonpilots in the F-III function as weapon systems operators and monitor radar and other instruments but do not ordinarily pilot the aircraft. Nonpilots in the T-38A have instruments similar to the pilot's, but at McClellan AFB they do not ordinarily utilize them. All of these fighter aircraft have ejection capability for both the pilot and nonpilot.

The cargo-type planes included the C-130 (turboprop cargo plane), the WC-135 (Boeing 707, weather reconnaissance) and $\mathrm{HH}-53$ (large rescue helicopter). Nonpilot aircrew on these planes included radio operators, navigators, loadmasters, pararescue specialists, 
and flight engineers; none have flight controls.

\section{Procedures}

Blood was taken from all subjects two times, once during the preflight briefing approximately 1-3 hr prior to takeoffs and again within 30 min of landing. All flights were preplanned routine flights, although the basic nature of the mission varied according to aircraft type. The time of each blood withdrawal and the time of takeoff and landing were recorded for each subject. After the second sample was taken, the subjects were asked to provide information on the type of mission flown, their crew position, rank, and comments about the flight.

\section{Hormone Assays}

All blood samples were allowed to clot at room temperature; serum was then collected and kept frozen until the assays were performed. Cortisol determinations were made by the competitive binding protein method of Murphy (12). All samples were run in duplicates in a single assay.

Serum testosterone levels were measured by radioimmunoassay according to the method of Frankel et al. (13) with minor modifications. All samples were run in duplicates in a single assay. The coefficient of variance was found to be $5 \%$.

\section{RESULTS}

At the time of the study, all subjects had considerable experience in their assigned crew position. The nonpilots on fighter planes had the least flying experience, 1588 $\mathrm{hr}$, compared to $3214 \mathrm{hr}$ for fighter pilots, $3882 \mathrm{hr}$ for cargo pilots, and $4018 \mathrm{hr}$ for nonpilots on cargo planes. These differences were not statistically significant.

All preflight blood samples were collected between 9:00 A.M. and 2:00 P.M. There was no significant difference between the preflight times of collection of samples for fighter crews and cargo crews (fighter $X=11: 35$ A.M.; cargo $X=10: 43$ A.M.). 
However, the cargo crews' postflight samples

were collected later in the day than

the fighter crews ${ }^{\wedge}[F(1,35)=20.85$,

$\mathrm{p}<0.01$; fighter $X=2: 41$ P.M., cargo

$X=5: 25$ P.M.). This reflected the longer

flight times of the cargo aircraft [cargo

$X=3.35 \mathrm{hr}$, fighter $X=1.70 \mathrm{hr}$ ); $\mathrm{F}$

$(1,35)=71.58, p<0.001]$.

Preflight cortisol levels were unaffected by crew position and aircraft type. As seen

in Figure 1, all groups of men had similar levels of cortisol. The postflight samples, however, revealed that the nonpilots had elevated plasma cortisol in relation to the pilots. This difference was statistically significant $[F(1,35)=8.95, p<0.01]$. Neither aircraft type nor the aircraft by crew position interaction was significant.

Differences in testosterone levels were found when aircraft types were compared. As seen in Figure 2, those men on fighter planes had lower testosterone levels than the men flying on cargo planes. This difference was statistically significant for the preflight levels of testosterone [F $(1,35)=5.48, p<0.05]$. However, this difference failed to reach the significance level for the postflight samples [ $F$ $(1,35)=3.81, p<0.10]$. No effect due to crew position for either pre- or postflight testosterone levels was seen.

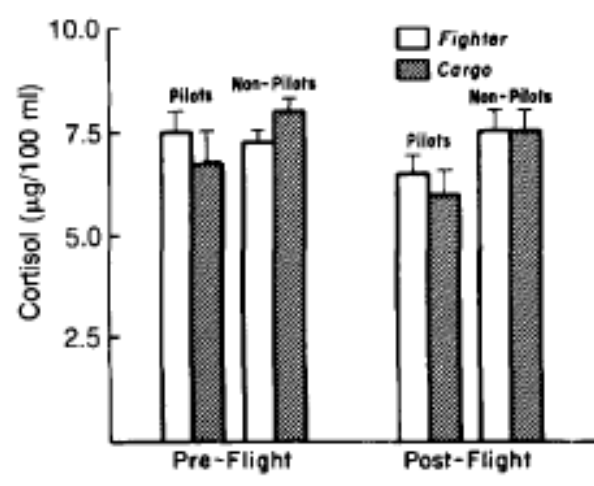

Fig. 1. Serum cortisol levels (mean \pm SEM). pre and postflight, for pilots and nonpilots of fighter and cargo aircraft.

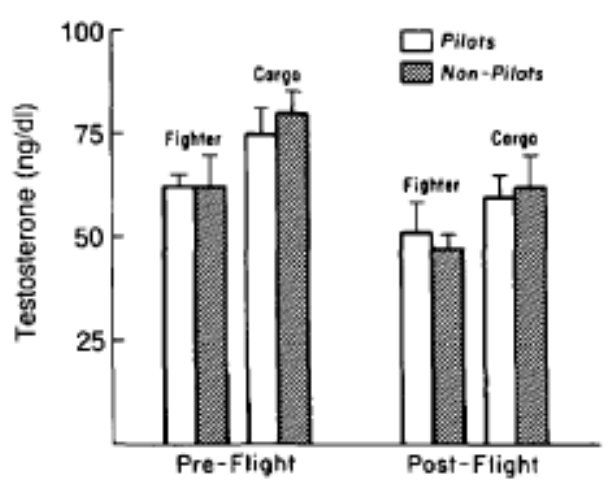

Fig, 2. Serum testosterone levels (moan \pm SEM), preand postflight, for pilots and nonpilots of fighter and cargo planes. 


\section{DISCUSSION}

The results of the present study, although based on limited samplings, indicate that both aircrew position and aircraft type can affect the psychoendocrine response to the exposure to mildly stressful conditions of routine flight. More extensive sampling of both flying and nonflying days would give a more complete profile of the endocrine differences in these men.

Several variables may be important in understanding the differences that were found in this report. Gal and Lazarus (11) offer the hypothesis that being engaged in a threat-related activity can be highly effective in reducing the physiologic response to a psychologic stressor. This idea has been used to explain the findings that helicopter medics (10) and enlisted Green Berets (14] had lower cortisol levels under combat conditions than did comparable groups of men in basic training. Both the medics and Green Berets spent considerable amounts of time engaged in the execution of their duties.

The role of responsibility may also be an important determinant of the physiological response to stressors. Officers in a Green Beret unit had higher levels of 17OHCS than the enlisted men in the same group (14). Also, naval aviators making their first aircraft carrier landings had higher serum cortisol levels than the nonpilot flight officers flying with them (1).

In the present study we found that the nonpilots, rather than pilots, had elevated cortisol levels after a routine flight. This study differs from that of Miller et al. (1) using naval aviators in at least two important aspects. The naval aviators studied by Miller were undergoing training in one of the most dangerous tasks of aviationcarrier landings. Additionally, the naval pilots were undergoing "qualification" flights, in which they either successfully landed on the aircraft carrier or else returned to shore for landing. While 
the pilots and flight officers were exposed to the same physical dangers, the pilots were exposed to the additional stressor of performing the required landing. In contrast, the pilots in the present experiment were flying routine missions and were not under pressure to perform a new task. The relatively low level of the physical and psychologic threat in the current study is reflected by cortisol levels falling within the normal range for both the pilot and nonpilot groups. That the pilots' cortisol levels in the present study were lower than the nonpilots' after the flight may be due to the fact that they had available to them a "threat-related coping activity" (11) that was not available to the nonpilots.

Diurnal variation cannot account for these differences in cortisol levels, since the sample times were the same for both pilots and nonpilots within aircraft types. The lack of a drop in the postflight cortisol samples obtained from the cargo nonpilots is especially striking, since their samples were collected during the time reported by Rose et al. (16) when cortisol levels are lowest.

The effects of a psychologic stressor on the testosterone levels in air crewmen is also of interest. In the present study, lower levels of serum testosterone were seen in the crews of fighter-type planes than in men flying on cargo planes prior to a routine flight and to a lesser extent after the flight. A difference in postflight sampling times between the two types of crews may well have masked comparatively lower testosterone levels in fighter crew samples since these men were sampled during the diurnal nadir reported by Rose et al. (16). This suppression of testosterone in the crews of the fighter planes may be due to chronic stress resulting from the conscious or unconscious perception that flying on fighter planes entails a fairly high degree of risk.

Examination of multiple hormonal systems in the same group of subjects provides 
a more complete profile of the physiologic responses to psychogenic stressors

(17). In the present study, cortisol and testosterone

levels were independent measures

of the stress occurring in response

to military flight. Although a suppression

of testosterone levels was seen in both pilots

and nonpilots of fighter-type planes,

only the nonpilots had elevated cortisol

levels. The coping activity of the pilots,

while effective in reducing their cortisol

levels in comparison to the nonpilots, does

not appear to be effective in dealing with

the stressors on a chronic basis as reflected

by serum testosterone. This is supported

the studies of Davidson et al. (9) and

Levine (2), where both suppressed testos-

terone levels and elevated cortisol levels

were seen in men making their first parachute

jump, but no correlation between

these hormone levels was found for the

individual men.

In addition to the variables studied

above, the personality type of the subject

may interact in the perception of stress by

these men. This may be reflected in the

selection procedure for the different per-

sonnel positions available in the U.S. Air

Force. Studying these variables could add

valuable behavioral information.

\section{REFERENCES}

1. Miller RG, Rubin RT, Clark BR, Crawford WR, Arthur RJ: The stress of aircraft carrier landings: 1.

Corticosteroid responses in naval aviators. Psychosom Med 32:581-588, 1970

2. Levine S: Cortisol changes following repeated experiences with parachute training. In Ursin $\mathrm{H}$, Baade

E, Levine S (eds), Psychobiology of Stress: A Study of Coping Men. New York, Academic, 1978

3. Dessypris A, Kuoppasalmi K, Adlercreutz H: Plasma cortisol, testosterone, androstenedione and luteinizing hormone $(\mathrm{LH})$ in a non-competitive marathon run. J Steroid Biochem 7:33-37, 1976

4. Rubin RT, Rahe RH, Arthur RJ, Clark BR: Adrenal cortical activity changes during underwater demolition team training. Psychosom Med 31:553-564, 1969 
5. Kreuz LE, Rose RM, Jennings JR: Suppression of plasma testosterone levels and psychological stress:

A longitudinal study of young men in Officer Candidate School. Arch Gen Psychiatry 26:479482.1972

6. Rose RM, Jenkins CD, Hurst M, Livingston L, Hall RP: Endocrine activity in air traffic controllers at

work. I. Characterization of cortisol and growth hormone levels during the day.

Psychoneuroendocrinology 7:101-111, 1982

7. Morville R, Pesquies PC, Guezennec CY, Serrurier BD, Guignard M: Plasma variations in testicular and adrenal androgens during prolonged physical exercise in man. Ann Endocrinol 40:501-510, 1979

8. Aono T, Kurachi K, Mizutani S, Hamarak Y. Uozomi T, Nakasima A, Koshiyamama K, Matsumoto K:

Influence of major surgical stress on plasma Levels of testosterone, luteinizing hormone and folliclestimulating hormone in male patients. J Clin Endocrinol Metab 35:535-542, 1972

9. Davidson JM, Smith ER, Levine S: Testosterone. In Ursin H, Baade E, Levine S (eds), Psychobiology of Stress: A Study of Coping Men. New York. Academic, 1978

10. Bourne PG, Rose RM, Mason JW: Urinary 17-OHCS levels. Data on seven helicopter ambulance medics in combat. Arch Gen Psychiatry 17:104-110, 1967

11. Gal R, Lazarus RS: The role of activity in anticipating and confronting stressful situations. J Hum Stress 1:4-20, 1975

12. Murphy BEP: Some studies of the protein-binding of steroids and their application to the routine micro and ultramicro measurement of various steroids in body fluids by competitive protein-binding radioassay. J Clin Endocrinol 27:973-990, 1967

13. Frankel Al, Mock EJ, Wright WW, Kamel F: Characterization and physiological validation of a radioimmunoassay for plasma testosterone in the male rat. Steroids 25:73-98, 1975

14. Bourne PG, Rose RM, Mason JW: $17-O H C S$ levels in combat. Special forces "A" team under threat of attack. Arch Gen Psychiatry 19:135-140, 1968

15. Rose RM, Bourne PG, Poe RO, Mougey EH, Collins DR, Mason JW: Androgen responses to stress. II. Excretion of testosterone, epitestosterone, androsterone and etiocholanolone during basic combat training and under threat of attack. Psychosom Med 31:418-436, 1969

16. Rose RM, Kreuz LE, Holaday JW, Sulak KH, Johnson CE: Diurnal variation of plasma testosterone and cortisol. J Endocrinol 54:177-178, 1972

17. Mason JW: "Overall" hormonal balance as a key to endocrine organization, Psychosom Med 30:791-808, 1968 